\title{
COMPRENDER EL PASADO ESTÉTICAMENTE: NIETZSCHE Y LA HISTORIA
}

\author{
Understanding the past aesthetically: \\ Nietzsche and History \\ Luis E. de Santiago Guervós \\ Universidad de Málaga
}

Resumen: Partimos de la base que, desde sus primeros escritos, se aprecia en el joven Nietzsche una especie de dialéctica que determina su discurso sobre la relación entre el presente y el pasado: se trata de la dialéctica entre la ciencia y el arte, entre el valor de los hechos interpretados objetivamente o la fuerza creadora e interpretativa del hombre, que tiene sus raíces más profundas en la vida. Desde esta perspectiva tratamos de explicar cómo la experiencia estética, en cuanto forma suprema de afirmar la existencia, pone de relieve lo que hay de afirmativo y creativo frente a una actitud indiferente o pasiva en relación al pasado.

Palabras clave: objetivismo - pasado histórico - estética - intérpretes excepcionales

ABSTRACT: We start from the premise that Nietzsche, from his first writings, maintained a kind of dialectics that determines his speech about the connection between the present and the past: it is the dialectics between science and art, between the value of facts interpreted objectively and the creative and interpretative power of man, which is deeply rooted in life. From this perspective we try to explain how the aesthetic experience, as the supreme way of affirming existence, highlights the affirmative and creative aspects in opposition to an indifferent or passive attitude in relation to the past.

Keywords: Objectivism - Historical Past - Aesthetics - Exceptional Interpreters

A la hora de plantearnos el problema de si en Nietzsche se da o se puede hablar de hermenéutica, no hay que olvidar que una filosofía como la suya, que gira en torno a la idea de interpretación, tiene que ocupar un lugar destacado en el pensamiento hermenéutico actual. Esto significa, como lo han puesto de relieve en reiteradas ocasiones Johann Figl ${ }^{1}$, Alan D. Schrift ${ }^{2}$, Hartmut Schröter ${ }^{3}$, Hofmann ${ }^{4}$, que la filosofía de Nietzsche no se puede entender, por una parte, sin tener en cuenta que la interpretación es un principio filosófico básico y un elemento de crítica fundamental frente a la metafísica tradicional y, por otra, que

1. Cf. J. Figl, Intrepretation als philosophisches Prinzip. Friedrich Nietzsches universale Theorie der Auslegung im späten Nachlass, Berlin: Walter de Gruyter, 1982.

2. Cf. A. D. Schrift, Nietzsche and the question of Interpretation, between hermeneutics and deconstruction, London: Routledge, 1990.

3. Cf. H. Schröter, Historische Theorie und geschichtliches Handeln. Zur Wissenschaftkritik Nietzsches, Mittenwald: Männder, 1982.

4. J. N. Hofmann, Wahrheit, Perspektive, Interpretation. Nietzsche und die philosophische Hermeneutik, Berlin: Walter de Gruyter, 1994 
en torno a ese principio se analiza la forma de experiencia vital que nos permite ver el mundo y la existencia de otra manera.

Jean Grondin acertadamente indicaba que «Nietzsche es tal vez el primer filósofo moderno que sensibilizó la conciencia para percibir el carácter fundamentalmente interpretativo de nuestra experiencia del mundo» ${ }^{5}$. Y se podría añadir todavía más. Ningún pensador antes que él abordó con tanta claridad y radicalidad el carácter de la interpretación y su dimensión hermenéutico-universal: no hay «hechos», decía Nietzsche, sólo interpretaciones; el mundo es el resultado de una interpretación; el sujeto es también una interpretación; todos los valores son interpretaciones; la historia es el arte de la interpretación pues se reduce a poner límites, a establecer épocas, fines, horizontes, prospectivas, a configurar plásticamente el pasado, etcétera.

Pero incluso desde una posición tan aparentemente distante de Nietzsche como la de Gadamer, es bastante significativo que se diga que el «desafío del pensamiento de nuestro siglo» es «el carácter interpretativo de toda vida y de todo conocimiento, relacionado con el nombre de Nietzsche» ${ }^{6}$. Y tampoco es casual que ese desafío fuese para Heidegger el leitmotiv de su propia filosofía, como lo confesaba su propio hijo. Por eso, no es extraño, que tanto Heidegger como Gadamer, siguiendo la estela de Nietzsche, lleguen a la conclusión de que la interpretación, "constituye la estructura originaria del 'ser-en-el-mundo'» ${ }^{7}$, y que muchos de los desarrollos posteriores de la filosofía hayan seguido este discurso: piénsese en las teorías freudianas, en las tendencias deconstructivistas, en la teoría del pensamiento débil, en el nuevo pragmatismo, etcétera.

Ese mismo desafío lo asumimos también hoy al descubrir en el pensamiento de Nietzsche implícitos hermenéuticos de gran alcance, sobre todo cuando analizamos uno de sus pilares fundamentales: la relación que se da entre el intérprete y el pasado, es decir, el significado de la historia y la tradición en la experiencia que tiene el hombre del mundo. No se trata, por tanto, de examinar críticamente si algo es verdadero o falso, ya que las oposiciones metafísicas han dejado de tener sentido, sino de desenmascarar ilusiones y engaños, es decir, de «sospechar», como decía Ricoeur, de todo aquello que se nos presenta como verdadero. El propio Gadamer también venía a enfatizar la relación mediadora que caracteriza a la interpretación: «¿No es la propia realidad el resultado de una interpretación? La interpretación es lo que ofrece la mediación nunca perfecta entre hombre y mundo, y en este sentido la única inmediatez y el único dato real es que comprendemos algo como 'algo'» ${ }^{8}$. Y es que ese carácter, siempre provisional de toda interpretación, condicionada por la situación histórica o la perspectiva individual, es lo que hace que la interpretación, como dice también Gadamer, sea una "aventura», y como toda aventura, siempre conlleve un riesgo peligroso'. Y ese riesgo, precisamente, es el que asume Nietzsche radicalizando la hermenéu-

5. J. Grondin, Introducción a la hermenéutica filosófica, Barcelona: Herder, 1999, p. 35.

6. Ibid., p. 29. H. G. Gadamer, «Nietzsche y la Metafísica», en Acotaciones hermenéuticas, Madrid: Trotta, 2002.

7. H. G. Gadamer, «Texto e Interpretación», en Verdad y método II, trad. de M. Olasagasti, Salamanca: Sígueme, 1992 [VM II], p. 327.

8. Ibid.

9. Ibid., p. 79. 
tica hasta extremos insospechados, con el fin de establecer fundamentos nuevos para una proyección optimista del hombre hacia el futuro, e inaugurando una nueva forma de pensar.

Nuestro punto de partida, entonces, se basa en que desde un principio, y sobre todo en sus primeros escritos, se aprecia en el joven Nietzsche una especie de dialéctica que determina su discurso sobre la relación entre el presente y el pasado: se trata de la dialéctica entre la ciencia y el arte, entre el valor de los hechos interpretados objetivamente o la fuerza creadora e interpretativa del hombre, que tiene sus raíces más profundas en la vida. Desde esta perspectiva tratamos a continuación de dilucidar cómo la experiencia estética, en cuanto forma suprema de afirmar la existencia, pone de relieve lo que hay de afirmativo y creativo frente a una actitud indiferente o pasiva en relación al pasado, al mismo tiempo que sostiene el despliegue de las potencialidades humanas.

\section{PUNTO DE PARTIDA: CONCIENCIA DE LA RADICAL HISTORICIDAD DE LA EXPERIENCIA HUMANA. EL PROBLEMA DE LA OBJETIVIDAD DE LA CIENCIA HISTÓRICA}

La crítica al objetivismo científico, que más tarde Habermas consideraría como una de las mejores contribuciones de la hermenéutica al pensamiento actual, es significativamente también una de las primeras experiencias filosóficas del joven Nietzsche y posiblemente el primer paso de una despedida de la filología entendida como ciencia.

El ajuste de cuentas que Nietzsche emprende contra el historicismo abre un nuevo camino en relación al lugar que debe ocupar la historia en la valoración de la existencia humana y a la perspectiva estética desde la que se contempla. Con su argumentación, Nietzsche se adelantaba a los planteamientos de la hermenéutica filosófica actual, poniendo en un primer plano la reivindicación de una forma de experiencia humana, la experiencia estética, por encima de cualquier planteamiento científico del pasado que tenía como finalidad la objetividad histórica y la formación de una conciencia histórico-científica contemporánea. En el fondo, el problema que se plantea no es ni más ni menos que la relación entre arte y ciencia, o de una forma más concreta, en el marco de su proyecto hermenéutico, la relación entre arte y filología, ámbito en el que se dilucida la relación del intérprete con el pasado.

Para Nietzsche, tanto el significado de la ciencia, como el de la religión, y el de la historia, en sus orígenes, es estético ${ }^{10}$ : son productos de la necesidad humana, expresión de la tendencia innata de huir de la realidad hacia mundos de ilusión, de imponer un orden a la experiencia con el fin de proporcionar la seguridad y el sustento que la existencia no tiene. En este sentido, la «verdad histórica» no es más que una perversión del impulso estético original que tomaba la apariencia por lo real, y fosilizaba la vida en forma de imagen fija. Lipperheide, por ejemplo, considera que se puede hablar de una «estética de la historia» en Nietzsche, «que se enfrenta a la filosofía de la historia optimista, a la posthistoria

10. FP I 29[192] y [194]. 
cultural del siglo XIX y a la posthistoria técnico-social del siglo $\mathrm{XX}^{11}{ }^{11}$ y Katrin Meyer, del mismo modo, piensa que se da también en las distintas formulaciones de Nietzsche una teoría estética de la historia ${ }^{12}$, como alternativa a los efectos "barbarizantes de la ciencia» ${ }^{13}$, contra el «exceso" de cientificismo y, sobre todo, contra la conciencia histórico-científica de sus contemporáneos.

Las ideas de juventud de Nietzsche referentes al problema de la historia y su relación con el arte quedan ya perfiladas y esbozadas en la «Lección inaugural» que pronuncia en la Universidad de Basilea, el 28 de mayo de 1869, bajo el título "Homero y la filología clásica». Allí se aprecia de una forma nítida cómo debían entenderse las relaciones entre el pasado y el presente, el proyecto de una «cultura viva», la posición de la filosofía en relación con el arte y la ciencia, que se había de enfrentar a los prejuicios de su época. Nietzsche estaba ya entonces convencido de que, entre la ciencia filológica que interpreta el pasado y la existencia humana, el arte era el único campo en el que podían plantearse los problemas de la ciencia. Frente a los excesos de la ciencia, de la historia o de la filología el hilo conductor era la vía estética. Él mismo proclama ya entonces: el arte dice: «la vida es digna de ser vivida", la ciencia dice: «la vida merece ser conocida» ${ }^{14}$.

Poco tiempo después estas mismas ideas eran expuestas, de una manera más radical y polémica en su primera gran obra, El nacimiento de la tragedia, de 1872, que es el referente práctico de la posición de Nietzsche frente a la investigación histórica académica y oficial. En aquel libro Nietzsche confiesa que se enfrentaba a un "problema nuevo", un "problema con cuernos»: "el problema de la ciencia», es decir, la ciencia entendida como algo «problemático». Pero ni siquiera dieciséis años después de haber escrito aquel libro renunciaba a lo que había sido su leitmotiv: "ver la ciencia con la óptica del artista, y el arte, con la de la vida..." ${ }^{15}$. Con lo cual nos estaba ya diciendo que la óptica del arte es capaz de desentrañar el sentido profundo del mundo y de la existencia mejor que el método de la ciencia, y que cualquier justificación de la vida y el mundo sólo es posible estéticamente. $\mathrm{O}$ en otros términos, que la esencia de la ciencia es el arte, y que la esencia del arte es el poder, o en última instancia, que la esencia del poder es la vida misma ${ }^{16}$. Éstas eran las tres perspectivas que habían convertido a Nietzsche en un centauro en el que se entrecruzaban ciencia, arte y vida. Pero añadía todavía más, resumiendo su posición firme: «el arte es la tarea suprema y la actividad propiamente metafísica de esta vida ${ }^{17}$, y como tal, decía un poco más adelante, "el arte es un suplemento de la ciencia».

Así pues, frente a la metafísica de la historia Nietzsche diseña una especie de «metafísica del arte», la «metafísica de artista», que define su perspectiva sobre la

11. C. Lipperheide, Nietzsches Geschichtstrategien. Die rhetorische Neuorganisation der Geschichte, Würzburg: Königshausen \& Neumann, 1999, p. 15.

12. Así titula su obra Katrin Meyer, Ästhetik der Historie. Friedrich Nietzsches «Von Nutzen und Nachteil der Historie für das Leben», Würzburg: Königshausen \& Neumann, 1998.

13. FP I 329: 19[25].

14. Homero y la filología clásica [HFC], trad. de L. Jiménez Moreno, Madrid: Ediciones Clásicas, 1995 , p. 52.

15. Ensayo de autocrítica (1886), en NT, trad. de A. Sánchez Pascual, Madrid: Alianza, 1986, p. 28. (Seguimos las traducciones de Andrés Sánchez Pascual para las obras publicadas de F. Nietzsche.)

16. C. F. Weizsäcker, Wahrnehmung der Neuzeit, München, 1983, p. 74

17. NT, p. 39. 
ciencia, la historicidad y la idea de desarrollo y progreso, y da un contenido vitalista, existencial y estético a su teoría sobre la historia ${ }^{18}$. Será la "óptica del arte», entonces, la que esboce en última instancia las líneas maestras de su «revolución estético-hermenéutica», que llevará a cabo en un primer momento de la mano de Schopenhauer y de su maestro Wagner, sin olvidar la contribución de la filosofía de Heráclito y de los presocráticos en general. Lo apolíneo y lo dionisiaco marcarán la referencia bipolar de esa teoría del arte que hace las veces de paradigma en la visión que tiene Nietzsche de la realidad. Posteriormente, en el escrito sobre la historia, la Segunda intempestiva, se amplía de una manera existencial lo que en El nacimiento de la tragedia se hacía de una manera metafórica y simbólica.

Partiendo de estos supuestos estéticos, es lógico que considere un «absurdo» tanto la objetividad de la ciencia como la «objetividad del historiador» ${ }^{19}$, la objetividad histórica. Varias son las razones. Pensar un acontecimiento o hecho histórico como algo "puro», como un «en sí», como una «contemplación desinteresada», o como un "proceso intelectual» sin más, supone una "superstición» si se cree que con ello se nos revela el verdadero sentido de las cosas. Por el contrario, habría que llenar de un nuevo contenido hermenéutico el término "objetivo", pues en realidad la objetividad es una "condición del historiador», es "contemplación artística», "el momento propiamente creativo de la obra de arte, un momento supremo de composición: durante el cual la voluntad duerme» ${ }^{20}$. Es por eso por lo que la filología no puede comprender verdaderamente la Antigüedad, pues se ha convertido en una ciencia enciclopédica; ha perdido su habilidad original para aplicar sus resultados de una manera crítica a la autocomprensión del presente cultural. El pasado, de este modo, se convierte en un objeto de investigación de una ciencia pura y no en una fuente para comprender nuestro presente, enjuiciarlo, a fin de superar nuestra época y, en última instancia, como objetivo principal, a nosotros mismos ${ }^{21}$. Esta renuncia de la filología pone de manifiesto una transformación con graves consecuencias: la ciencia filológica es un fin en sí mismo, no un medio al servicio de la vida, que excede cualquier medida de control y bloquea sus cualidades críticas. Como diría más tarde Gadamer: «La ceguera axiológica propia del objetivismo histórico desemboca así en el conflicto entre el mundo histórico enajenado y las fuerzas vitales del presente» ${ }^{22}$.

La nueva objetividad que propone Nietzsche, entonces, no es la objetividad de la ciencia, garantizada por la neutralidad del sujeto y su distancia, sino la objetividad del artista y su «interés». En la Segunda consideración intempestiva, dice:

Suele entenderse generalmente esta palabra [objetividad] como un estado en el que el historiador que ve la sucesión de motivo y consecuencia con una pureza tal que no ha de ejercer ningún efecto sobre su propia subjetividad. Pensamos en el fenómeno estético del desapego liberador de uno mismo y de los intereses personales en que el pintor, en medio de un paisaje tormentoso bajo rayos y truenos, o

18. K. Meyer, Aesthetik der Historie, Würzburg: Königshausen\&Neumann, 1998, p. 99.

19. FP I 29[96].

20. Ibid.

21. Cf. mi trabajo «Homero y la filología clásica. Arte y filosofía: los centauros del joven Nietzsche»: Anales del Seminario de Historia de la Filosofía 15 (1998), 149-167.

22. H. G. Gadamer, «El problema de la historia en la reciente filosofía alemana» (1943), en VM II, p. 38 . 
sobre un mar embravecido, contempla allí la imagen que tiene en su interior, es decir, sumergiéndose completamente en las cosas.

Y un poco más adelante puntualiza de una forma más expresiva:

[...] no es más que una superstición creer que el cuadro dado a ese hombre por el objeto muestra realmente la verdad de las cosas. iAl menos que se espere que en tales momentos los objetos se pinten o se fotografíen a sí mismos por su propia actividad sobre un medio puramente pasivo! ${ }^{23}$.

Es en este sentido artístico en el que Nietzsche pretende entender la objetividad, que deja de ser una mera «frase» para convertirse en una «propiedad positiva». No hay que entender, sin embargo, la tarea del historiador como un ojo artístico en calma, callado, imperceptible, pues es completamente absurdo que a quien no le «interesa» un momento del pasado, porque tiene que salvaguardar la objetividad de los hechos, sea aquel que mejor nos puede describir el pasado histórico. Para Nietzsche hay dos intereses del conocimiento distintos entre la consideración estética de la historia y la consideración científica. Ésta busca ante todo la neutralización del sujeto, mientras que la primera sabe transformar en verdad artística lo diferente y lo extraño, o lo que es lo mismo, sabe hacer de la comprensión del pasado una «obra de arte». El saber artístico y la necesidad de la apariencia se oponen así a la disolución de lo desconocido en el concepto. De este modo, la nueva objetividad que auspicia Nietzsche sería algo así como la «composición» que plasma el artista en un lienzo, es decir, el resultado en un cuadro artístico, «pero todavía no históricamente verdadero» ${ }^{24}$. Partiendo de esta nueva idea de objetividad y de su perspectiva estética, es necesario comprender el modo de ser del intérprete para poder percibir el alcance de su planteamiento frente al ideal de objetividad de la ciencia histórica.

\section{LA POSICIÓN DEL INTÉRPRETE EN RELACIÓN CON EL PASADO HISTÓRICO}

Esta nueva forma de objetividad hermenéutica que postula Nietzsche plantea de entrada algunos interrogantes que hay que aclarar. ¿Es subjetivista su posición? ¿Tenía razón Heidegger cuando interpretaba su filosofía como la consumación de la filosofía subjetiva? ¿El sentido de las cosas se descubre o se crea? ¿Se puede afirmar que su hermenéutica es una "proyección perspectivista» o un «acto creador»? La respuesta a estos interrogantes nos la proporcionará un análisis o descripción de lo que para Nietzsche es el modo de ser del intérprete o historiador, respuesta que, como veremos, tiene mucho que ver con su manera de ver el arte.

Nietzsche trata de demostrar cómo las creencias de la ciencia, o «los falsos hijos de la ciencia» ${ }^{25}$, como él llama a los conceptos científicos, son entidades imaginarias, muchas veces resultado de un hábito lingüístico, otras producto de la necesidad, ilusiones que es necesario desenmascarar. En primer lugar, una hermenéutica radical como la suya implica el abandono de la noción del sujeto

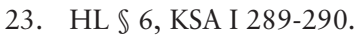

24. FP I 29[96].

25. GM I, $\mathbb{S} 13$, p. 52. 
entendido como unidad ${ }^{26}$ : el «sujeto» — dice- ha sido el mejor «dogma» ${ }^{27} \mathrm{a}$ lo largo de toda una tradición. Pero la verdadera realidad es otra, pues como resume en La genealogía de la moral: «no hay ningún 'ser' detrás del hacer, del actuar, del devenir; el 'agente' ha sido ficticiamente añadido al hacer, el hacer es todo» ${ }^{28}$. La superación de la dicotomía sujeto-objeto, que en Nietzsche tiene raíces gramaticales y metafísicas, y en cierta medida morales, le lleva entonces a pensar la interpretación como un proceso o un devenir sin sujeto: «la interpretación misma, como una forma de voluntad de poder, tiene existencia (pero no como un 'ser', sino como un proceso, un devenir) como un afecto» ${ }^{29}$.

Por eso el término interpretación y perspectiva no caracterizan el punto de vista privado de un individuo, sino que designan el horizonte interpretativo particular de una forma de vida, que se define como un centro de valoración que abarca desde el nivel de los afectos hasta las organizaciones culturales, sociales y políticas. Así pues, el individuo es una configuración de perspectivas. "Todo es subjetivo', dices tú; pero incluso esto es una interpretación. El 'sujeto' no es nada dado, sino algo añadido, fabricado ${ }^{30}$. En esto Nietzsche es claro y muchas veces olvidamos, prisioneros del lenguaje metafísico, que cuando trata de dar una respuesta a la pregunta inexorable de cuál es el sujeto de las interpretaciones, afirma: "¿Quién interpreta? - Nuestros afectos» ${ }^{31}$. Entonces no se puede hablar de un sujeto de la interpretación, sino de afectos, de impulsos y de instintos jerarquizados, en el ámbito de un organismo donde unos dominan sobre los otros y nunca abandonan ese estado tensional que caracteriza a la «voluntad de poder».

Para explicar ese modo de ser del intérprete y su relación con el pasado, recurre Nietzsche una vez más a la vía del arte, en concreto al arte visto desde la perspectiva, no de la obra de arte, sino desde el artista. La interpretación se entiende entonces como una pasión, una experiencia que hacemos, un proceso en el que no hay sujeto como tal, pero sí ese pathos que en Nietzsche está estrechamente ligado a las peculiaridades del artista dionisíaco: su ímpetu, su exhuberancia, su exceso. En este sentido, el momento creativo «más poderoso y espontáneo» está en el interior del artista, es como la experiencia del pintor que «en medio de un paisaje tormentoso bajo rayos y truenos, o sobre un mar embravecido, contempla allí la imagen que tiene en su interior ${ }^{32}$. Sería absurdo pensar que el hombre en ese estado de «embriaguez» dionisíaca se representase las cosas tal como son, en su propia esencia. El resultado de esa experiencia nunca puede ser, en el caso de la interpretación del pasado, una verdad histórica. Ese acto creativo tiene entonces como resultado, como ya vimos, según Nietzsche, «un cuadro artísticamente verdadero, no históricamente verdadero» (ibid.) y ese «impulso artístico» lo compara también con una «red» que el hombre va tejiendo sobre el pasado, como el dramaturgo teje la trama.

26. Cf. G. Vattimo, Mas allá del sujeto, Barcelona: Paidós, 1989, p. 43

27. GM I, $\mathbb{\$} 13$, p. 53.

28. Ibid., p. 52.

29. FP IV 2 [151] (VP $\$ 556)$.

30. FP IV 222: 7[60] (VP \$481).

31. FP IV 134: 2[190].

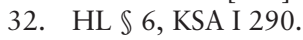


Así pues, pensar con objetividad el pasado es, dice Nietzsche, «el trabajo del dramaturgo; pensar una cosa con otra y entretejer los elementos en un todo único, con la presunción de que la unidad del plan se debe poner en los objetos si no está ya en ellos». Y citando a Grillparzer afirma que el conocimiento del pasado es visión dramatizada, pues el pasado ${ }^{33}$ no es otra cosa que el modo en que el espíritu aprehende hechos, vincula cosas, reemplaza lo ininteligible por lo inteligible, pone sus ideas de causalidad en el mundo, etc. En un fragmento de 1878 dice rememorando NT:

En otro tiempo creí que el mundo, considerado desde un punto de vista estético, se asemejaba a un espectáculo dramático y como tal había sido ideado por su autor, pero que como fenómeno moral era un fraude: por eso llegué a la conclusión de que sólo como fenómeno estético podía justificarse el mundo ${ }^{34}$.

No es extraño, entonces, que los pensadores e intérpretes contemporáneos hayan comenzado a comprender que la física, por ejemplo, es una interpretación más bien que una «explicación» que pintase el mundo objetivamente ${ }^{35}$. Lo que han hecho hasta ahora los físicos no ha sido precisamente arte. Sus modos de interpretación han sido "malos», puesto que imaginan que las leyes de la física son leyes que existen en la naturaleza: "Que las cosas tengan una constitución en sí, fuera de la interpretación y de la subjetividad, es una hipótesis idílica [...] presupone que la interpretación y subjetividad no son esenciales» ${ }^{36}$. Y esto significa, según él, que "nosotros sólo podemos comprender un mundo que nosotros mismos hemos hecho " ${ }^{37}$, de tal manera que «a este mundo creado por nosotros no corresponde ninguna supuesta 'realidad propia', ni un 'en sí de las cosas' ${ }^{38}$.

Por lo tanto, el sentido de las cosas es puesto por el arte, ya que el modo de ser del intérprete como artista es realmente lo que decide sobre las cosas, y el que ofrezcan solamente la posibilidad de entreverlas en perspectiva ${ }^{39}$. De este modo, la hermenéutica de Nietzsche no es tanto el proceso de la reconstrucción de los objetos, sino el de su constitución. El mismo Gadamer plantea la cuestión en estos términos: "¿̇la interpretación es una posición (einlegen) de sentido y no un descubrimiento (finden) de sentido?» ${ }^{40}$. Para Nietzsche, las cosas son obra del sujeto que las representa, que las quiere, que las experimenta, pero también el sujeto es algo "creado", el sujeto se ha convertido en «una fábula, una ficción, un juego de palabras» ${ }^{41}$. En este sentido,

el hombre proyecta su impulso de verdad, su «meta» en un cierto sentido fuera de sí como mundo ente, como mundo metafísico, como «cosa en sí», como mundo ya

33. Ibid.

34. KSA VIII 30[51].

35. MBM $\$ 14$.

36. FP IV 243: 9[40] (VP $\$ 560)$.

37. KSA XI 25[470] (VP \$ 495).

38. KSA XI 609.

39. Cf. GC $\$ 299$.

40. H. G. Gadamer, «Texto e interpretación», VM II, p. 328.

41. CI $\$ 3$. 
existente. Su necesidad de creador inventa el mundo en el que trabaja, lo anticipa: esta anticipación («esta fe» en la verdad) es su sustento ${ }^{42}$.

Y en el más puro estilo feuerbachiano afirma: «¿Sabes tú que cada una de las propiedades de los hombres y de las cosas, a las que tú ahora les das tus más bellas palabras, admite sin más, que son tus propiedades? ${ }^{43}$.

Sin embargo, no parece que esa disyuntiva que plantea Gadamer haya que entenderla en un sentido excluyente. Es cierto que en muchos pasajes Nietzsche afirma que las cosas tienen sentido porque nosotros lo ponemos, las cosas son bellas, porque nosotros las embellecemos, pero al mismo tiempo, en virtud de esa falta de autoconciencia de nuestra capacidad artística y creadora, descubrimos también el sentido y la belleza que pusimos en la cosas. Con esto, éno parece que Nietzsche también está aplicando la dialéctica del círculo hermenéutico de una manera productiva, como pedía Heidegger, cuando afirma que nosotros en realidad al comprender o interpretar estamos percibiendo sólo lo que nosotros previamente hemos puesto? Y si percibimos lo que hemos puesto, ¿no hay una cierta dirección en la comprensión determinada por el sentido de nuestras preguntas? En realidad, Nietzsche no parece que esté muy distante en algunos aspectos de las formulaciones actuales de la hermenéutica, concretamente, la gadameriana, pues ¿qué son los prejuicios sino proyecciones sobre las cosas, anticipaciones de sentido que esperan su confirmación de las cosas mismas? ${ }^{34}$.

Decía Grondin que la cosa no puede hablar ella misma más que a través de «mis proyectos de inteligibilidad» ${ }^{45}$. El artista no descubre lo bello en las cosas, sino que es su proyección lo que lo crea. O descubre la belleza de las cosas cuando toma conciencia de que es él el que crea lo bello, pues no hay belleza en sí. Si la hermenéutica se redujese a un simple «descubrimiento», entonces tendríamos que pensar en la existencia de la cosa en sí, y que hay cosas en sí bellas independientes del sujeto que las contempla. Por eso, se puede decir que el mundo no tiene patrones objetivos, sino que es más bien puesto por el arte, ya que el artista es el único que decide sobre las cosas. Son nuestras leyes las que colocamos en el mundo, y sólo a través de un poder lógico-poético dirigimos las perspectivas a todas las cosas y así nos mantenemos en la vida. Esto no quiere decir, sin embargo, que no haya «un pasado». No lo hay como un «en sí», como algo que se distingue de los individuos que hablan sobre la tradición, interpretan o comprenden, sino sólo como algo creado por ellos: «a este mundo creado por nosotros no corresponde ninguna supuesta 'realidad propia', ni un 'en sî' de las $\operatorname{cosas}^{\prime} »^{46}$, pues el sujeto mismo es el que hace que las cosas lleguen a ser $\operatorname{cosas}^{47}$.

La historia, entonces, hay que entenderla como un «acontecimiento estético» en cuanto a su forma de realización concreta y como tal fenómeno estético indica que «la historia es una forma de expresión subjetiva de la vida que no sólo

42. FP IV 261: 8[91].

43. Agosto de 1879, KSA VIII 611: 44 [1].

44. H.-G. Gadamer, Verdad y Método (WM), trad. de A. Agud y R. Agapito, Salamanca: Sígueme, 1997, p. 252

45. J. Grondin, L'universalité de l’herméneutique, Paris: PUF, 1993, p. 169.

46. KSA XI 609.

47. FP IV 243: 9[41]. 
da una explicación sobre la historia, sino también sobre el historiador ${ }^{48}$. En este mismo sentido Sloterdijk afirmaba que «la descripción de nuestra posición histórica determina la cualidad de nuestra actitud histórica» ${ }^{49}$. Por consiguiente, del pasado podemos hablar sólo de un modo antropomórfico, en la medida en que es un reflejo de la humanidad, como si fuera el «eco infinitamente quebrado de un sonido original» ${ }^{50}$. Por eso, nuestros reflejos en el mundo se confunden con verdades objetivas, porque el hombre se olvida de sí mismo como sujeto y, de hecho, como sujeto artísticamente creador $^{51}$. La capacidad para la verdad se une así a la producción estética, que es lo que viene a ser toda producción humana, es decir, la creación de imágenes. ¿Es la historia, entonces, un antropomorfismo? Así lo da a entender el propio Nietzsche cuando afirma en una nota de 1872 que «el proceso de toda religión, de toda filosofía y de toda ciencia frente al mundo: comienza con los antropomorfismos más toscos y no cesa nunca de refinarse ${ }^{52}$, y un poco más adelante añade: «El hombre conoce el mundo en la medida en que él se conoce: es decir, la profundidad del mundo se desvela en la medida en que él se maravilla de sí mismo y de su complejidad» ${ }^{53}$.

Teniendo en cuenta lo dicho hasta ahora, ¿no tendríamos que definir el pasado como el modo o la manera en que el intérprete aprehende los hechos? ¿Y acaso no se comporta el historiador, lo mismo que el filósofo, como un artista que continuamente despliega en la práctica su iniciativa creadora? El arte, en realidad, es una forma de recrear el mundo, que se justifica, lo mismo que la existencia, sólo estéticamente. En la medida en que el arte es «la actividad propiamente metafísica de la vida», el intérprete, como el artista, no está obligado a interpretar de una manera correcta lo que ve y observa, pues lo que hace que las obras de arte sean arte no es necesariamente su fidelidad a la realidad, o la imitación de la naturaleza.

Pero como ya hemos apuntado, para Nietzsche lo verdaderamente importante en el arte es el proceso creador, la perspectiva del artista, cuando se trata de interpretar el pasado. Está claro que aquí no interesa tanto el pasado en cuanto pasado, sino sobre todo el proceso de la interpretación misma, que es un proceso infinito pues nunca llega a cerrar el campo de sentido de las cosas. La interpretación, por lo tanto, es algo que siempre está en marcha, que no concluye nunca, precisamente porque se trata de un proceso, de un devenir o un acontecer. Pero Nietzsche matiza el sentido de ese proceso, puesto que mediante él el percibir consciente y su perspectivismo, como la voluntad misma, produce sus objetos.

Así pues, al negar que lo dado tenga un estatus privilegiado, el camino queda abierto al juego creativo de las interpretaciones, cada una de las cuales abre un horizonte particular de significado y valor, llevando el conocimiento hasta el infinito. He aquí el carácter de apertura hermenéutica que se da, desde la perspectiva de Nietzsche, en todo proceso de interpretación. Frente al «espectador

48. Cf. K. Meyer, op. cit., p. 123.

49. P. Sloterdijk, El pensador en escena. El materialismo de Nietzsche, trad. de G. Cano, Valencia: Pre-Textos, 2000, p. 55.

50. KSA I 883.

51. Ibid.

52. FP I 348: 19[115].

53. FP I 350: 19[118]. Cf. K. Spiekermann, Naturwissenschaft als subjektlose Macht? Nietzsches Kritik physikalischer Grundkonzepte, Berlin: Walter de Gruyter, 1992, pp. 44 ss. 
desinteresado» kantiano, como paradigma de la objetividad, Nietzsche opone a Argos, el monstruo de cien ojos que ha dominado sus pros y sus contras ${ }^{54}$. No hay límite en los modos en que el mundo puede ser interpretado en virtud de la visión perspectivista de toda existencia y del pluralismo interpretativo ${ }^{55}$. Este reconocimiento de las posibilidades interpretativas ilimitadas sanciona una aproximación pluralista de la interpretación, pues, como dice en La gaya ciencia, "no podemos sustraernos a la posibilidad de que él encierre en sí interpretaciones infinitas ${ }^{56}$. Esto quiere decir que el mundo, como cualquier texto, está siempre abierto a nuevas interpretaciones. No es extraño, por eso, que a la hora de confrontar esta manera de entender la realidad con el modo de ver las cosas de la ciencia insista una vez más:

La verdad no es algo que exista y que se ha de encontrar, descubrir, sino algo que se ha de crear y que da el nombre a un proceso [...]: introducir la verdad como un processus in infinitum, un activo determinar, no un tomar conciencia de algo que sea «en sí» fijo y determinado. Es una palabra para la «voluntad de poder $»^{57}$.

Detrás de este pluralismo interpretativo, que Hofmann acertadamente califica de "pluralismo tolerante» ${ }^{58}$, se da como un modo de vida impuesto para que las fuerzas puedan sobrevivir. Ese carácter pragmático que Nietzsche introduce en sus planteamientos radicales, como una salida a las posibles paradojas que generan, nos permite comprender mejor el alcance de su hermenéutica. En cierto sentido, podríamos definir esa visión perspectivista de la realidad y del pasado que tiene Nietzsche en términos de "pragmatismo perspectivista", puesto que, en definitiva, conocer es introducir o poner un sentido en las cosas para plegarlo a nuestros intereses vitales. Por eso, Nietzsche insiste en que en el caso de la hermenéutica la historia tiene que estar «al servicio de la vida», de lo contrario no saldríamos de esa enfermedad del siglo que invadía en su época todas las esferas de la vida. De ahí que sean precisamente las necesidades vitales las que marquen la pauta del valor de nuestras interpretaciones, o en última instancia que sea la vida el criterio último de la historia. En La gaya ciencia lo expresa con rotunda claridad:

[...] nosotros hemos preparado para nosotros mismos un mundo en el que podamos vivir - poniendo cuerpos, líneas, planos, causas y efectos, movimiento y reposo, forma y contenido: sin estos artículos de fe nadie podría ser capaz de vivir. Pero eso no los prueba. La vida no es un argumento; las condiciones de vida pueden incluir el error ${ }^{59}$.

Si nos atenemos a la terminología gadameriana, la hermenéutica en Nietzsche se perfila entonces como una "proyección de sentido». Sin embargo, Nietzsche matiza todavía más: esa proyección es el resultado de una experiencia. De mane-

54. HH II, $\mathbb{S} 223$.

55. Sobre el pluralismo interpretativo cf. A. Schrift, op. cit., p. 180.

56. GC $₫ 374$.

57. FP IV 9[91].

58. J. N. Hofmann, op. cit., p. 47.

59. GC \121; MBM \39; EH, sec. 3 . 
ra que se puede decir que el significado que nosotros atribuimos, por ejemplo, a la Antigüedad o al pasado, depende de nuestra propia experiencia. En Nosotros los filólogos, describe esto como la «antinomia de la filología»:

Hemos comprendido siempre la Antigüedad a través del presente - ¿vamos a comprender ahora el presente a través de la Antigüedad? Más correctamente: hemos explicado la Antigüedad sobre la base de lo que nosotros hemos experimentado, y sobre la base de una Antigüedad así creada, nosotros hemos juzgado y aseverado lo que hemos experimentado. La experiencia es entonces sin duda el presupuesto indispensable para ser un filólogo, es decir, primero tú has de ser un hombre antes de poder ser productivo como filólogo ${ }^{60}$.

Este texto viene a resumir lo que hasta ahora hemos definido como modo de ser del intérprete-historiador. "Primero has de ser un hombre», dice Nietzsche. ¿Qué significa esta propuesta antropológica de Nietzsche? A veces nos olvidamos que toda su filosofía se asienta sobre esta prioridad inmediata. No es posible comprender e interpretar si no ponemos como punto de partida al hombre de carne y hueso con sus afectos, sus instintos e impulsos, sus pasiones, en definitiva, tenemos el hilo conductor del cuerpo como fundamento de cualquier posible interpretación. Ya lo decía Goethe, y es algo que a Nietzsche le queda grabado. No podremos más de lo que somos. Según somos así comprendemos. Del eslogan de Goethe "se debe ser algo, para hacer algo", se desprende el principio fundamental del perspectivismo nietzscheano: «se debe ser algo, para comprender algo", porque en realidad, Nietzsche, como Heidegger, piensa que en el acto de la comprensión está envuelta todo la existencia. Y esto es lo que falta, precisamente, a la filología y a la ciencia histórica de su época. Nietzsche es un predecesor de esta concepción de la hermenéutica que en Gadamer llega a su completa expresión, porque está al servicio de la vida.

Esta idea es algo que estuvo muy presente ya en los primeros escritos de Nietzsche. Cuando en el Ensayo de autocrítica de 1886 explicaba algunas claves de El nacimiento de la tragedia, decía que había compuesto el libro, y había planteado su interpretación sobre la tragedia, "desde las experiencias...». Comenzó con una hipótesis metafísica sobre el significado de la música, pero en el fondo lo que había allí era una "experiencia psicológica». Años después, cuando enfrentaba su visión de la historia a las teorías historicistas que dominaban su época insiste en las mismas ideas:

Mi modo de relatar la historia es actualmente relatar mi propia experiencia con motivo de tiempos y gente pasados. No hay nada coherente sobre ello - Yo he comprendido unas pocas particularidades, nada más. Nuestros historiadores literarios son aburridos, porque se esfuerzan en hablar y juzgar de todo, incluso cosas de las que ellos no tienen experiencia ${ }^{61}$.

Así pues, todo encuentro con el pasado a través de la interpretación tiene que ver con una experiencia de afectaciones sucesivas. Pero esa experiencia de ser un sujeto que se crea y transforma a sí mismo al mismo tiempo que crea y

60. KSA VIII 3[62].

61. KSA VIII 30[60]. Cf. también GC $\$ 319$. 
transforma las cosas, es decir, lo sido en lo que será, constituye un elemento esencial de la configuración de la historia.

Llegados a este punto, señalamos en este contexto algo que apunta ya desde el principio del pensamiento de Nietzsche a lo que sería su eterna obsesión: la superación del hombre. Cuando Nietzsche habla del intérprete y de la interpretación del pasado histórico no deja de tener siempre presente la idea de la necesidad de una "gran potencia artística» que sea capaz de elevarse por encima de las cosas, ir más allá de ellas, y que pueda convertir su investigación en «un abismarse amoroso» en los datos empíricos, en última instancia, esa nueva forma de hacer historia nos llevaría a una "continua poetización de los tipos dados». ¿Qué quiere decir, entonces, que la objetividad de los hechos depende de la fuerza histórica o del «impulso artístico»? ¿Cómo se expresa ese «impulso artístico en el hombre»? En otras palabras: ¿qué lugar ocupan en nuestra relación con el pasado los que podríamos denominar «intérpretes excepcionales»?

\section{LOS SERES EXCEPCIONALES COMO VERDADEROS INTÉRPRETES DEL PASADO}

Hasta ahora hemos venido manteniendo que la hermenéutica de Nietzsche se comprende mejor desde la perspectiva estética, y que el modo de ser del intérprete tiene su referente en el modo de ser del artista. En este contexto, como es habitual en el joven Nietzsche, no podemos obviar la transposición de sus ideas sobre el genio al ámbito hermenéutico. Supone realmente una novedad hermenéutica el relieve que alcanza en Nietzsche la figura del intérprete excepcional o el "gran intérprete». Se trata aquí simplemente de equiparar la figura del «genio» en el ámbito de la estética, a la figura del artista-intérprete, que tiene una visión especial de la historia y del pasado y que comprende por encima de los demás. Si para él la hermenéutica es un arte, el arte de interpretar el pasado, y el artista-intérprete ocupa un lugar privilegiado, no es extraño que los «espíritus más excepcionales», es decir, aquellos que mediante el impulso artístico entretejen el pasado y lo llevan a la unidad estética, a la nueva objetividad, adivinarán «lo que es digno de saberse del pasado, lo que es digno de conservarse y lo que es grande» ${ }^{62}$.

Por lo tanto, el intérprete-historiador no es un simple observador que mide los hechos del pasado, o alguien que se encuentra entre los que simplemente acumulan los datos, registran los hechos y hablan de ellos objetivamente, a los que Nietzsche llama los «trabajadores» de la historia, sino el «gran hombre» que tiene una fuerza o poder para volver la mirada hacia atrás y colocar de nuevo sobre la balanza los «miles de secretos del pasado que salen de sus escondrijos - hacia $s u$ sol» ${ }^{63}$; y en esa medida, en virtud de sus cualidades superiores, podrá ser capaz de conocer lo que es «grande» y lo que hay que conservar. Ese es el «gran intérprete», es decir, aquel que ha vivido de una manera más grande, más noble y superior, cuya experiencia es tan grande que se desborda, como en el artista, para expresar algo.

Dentro de esa misma lógica Nietzsche llega incluso a decir que la grandeza de los acontecimientos depende también de la grandeza del historiador-artista

62. HL $₫ 6$, KSA I 294.

63. Ibid. 
que reconstruye los hechos históricos, pues según el principio estético, «lo semejante se descubre por medio de lo semejante», el verdadero intérprete del pasado tiene que poseer

la fuerza de volver a formular lo ya conocido como algo nunca antes visto y anunciar lo general de una manera tan sencilla y profunda que haga pasar lo profundo como simple y lo simple como profundo. No se puede ser al mismo tiempo un gran historiador, un artista y una cabeza hueca ${ }^{64}$.

A esto se llama «hacer historia», que es lo que hace el historiador-artista cuya meta no es tanto la objetividad de los hechos históricos, sino la manifestación de su fuerza vital y el poder de la vida. Así pues, el intérprete se debe medir en la grandeza del pasado, pero al mismo tiempo la grandeza del pasado se constituye sólo según el patrón o criterio de él. Por eso, el sentido del pasado adquiere esa especial relevancia en los momentos creativos, en los que se pone de manifiesto la grandeza (Die Grösse). Y a su vez esos momentos excepcionales son los que forman y aseguran esa cadena de interpretaciones diversas que llegan hasta el presente.

Que los grandes momentos forman una cadena, que éstos como una cordillera unen a la humanidad a lo largo de milenios, que para mí lo más grande de un tiempo pasado también es grande, y que se cumpla la creencia, henchida de presentimiento, del ansia de gloria: tal es el pensamiento fundante de la Cultura ${ }^{65}$.

En este sentido, Nietzsche espera que llegará un tiempo en el que «dejaremos sabiamente de lado todas esas construcciones de 'procesos del mundo' o de la 'historia humana', un tiempo en el que ya no se considere a la masa, sino de nuevo a los individuos, los cuales forman una especie de puente sobre la corriente desértica del devenir» ${ }^{66}$ y construirán un diálogo como entre grandes espíritus. Esto tiene algo que ver realmente con aquella «república de genios» de la que hablaba Schopenhauer:

[...] un gigante llama a otro a través de los intervalos desiertos de las épocas, y serenamente en medio de la petulancia de enanos que gruñen debajo de ellos, continúa el diálogo de espíritus en las alturas. La tarea de la historia consiste en ser la mediadora de éstos prestando sus fuerzas y proporcionando cada vez más la ocasión para la producción de lo grande. No, la meta de la humanidad no puede colocarse en el final, sino solo en sus más altos ejemplares ${ }^{67}$.

Los individuos ejemplares, por lo tanto, se colocan en el centro de la cadena de los eventos históricos. De esta manera, los historiadores no solamente preservan la memoria de la grandeza del pasado, sino que también redescubren las «posibilidades bellas de la vida». De ahí que aquel que narra los eventos del pasado para los fines de la cultura debe ser no sólo historiador, sino también ar-

64. HL $\mathbb{6}$, KSA I 294. Cf. también MBM, «Nosotros los doctos», $\mathbb{S} 204$ ss.

65. KSA I 756.

66. HL $\$ 9$, KSA I 317.

67. FP I 472: 29[52]. 
tista, incluso filósofo. Porque no solamente debe poseer una intuición profunda para su materia, sino poseer «gran facilidad artística, visión creativa, absorción amorosa en los datos empíricos, capacidad de imaginar el desarrollo posterior de un tipo dado ${ }^{68}$. Pero, además, y sobre todo, el historiador-artista tiene, en primer lugar, que dirigir la mirada hacia su época, hacia el presente, si quiere llegar a comprender el pasado. Y luego, tiene que haber llegado a su «mayoría de edad», una exigencia para todo aquel que tenga el valor de atreverse a interpretar el pasado. Formulado en forma de imperativo categórico: «Sólo desde la fuerza poderosa del presente tenéis el derecho de interpretar el pasado» ${ }^{69}$.

Hay otra serie de condiciones que Nietzsche atribuye al intérprete excepcional, por ejemplo, la de la libertad. Para evitar que las fuerzas del pasado debiliten la fuerza vital del presente y provoquen esa «enfermad histórica» que padece la época, es necesario «ser libres» frente a la historia, es decir, que el poder libre del hombre se siga manifestando en su actividad creadora, y que el que cree la historia esté por encima de ella. Pero el que crea la historia como artista, no puede quedar prisionero de su propio pasado, aunque lo determine, pues el hombre ha de superarse siempre a sí mismo. Esto es lo que para Nietzsche significa el espiritu nuevo, volver la historia contra la historia, y de nuevo retrotraernos por encima de nuestra cultura alejandrina hasta los modelos originarios de la Antigüedad griega, donde encontraremos una cultura esencialmente «no-histórica», y por lo tanto llena de «vida».

El problema planteado sobre los «intérpretes excepcionales», que tiene en el genio su concreción en los primeros escritos del joven Nietzsche, adquiere una nueva dimensión a partir de Humano demasiado humano. Ahora son los espíritus libres los que tratan, mediante un impulso, de emanciparse de la tradición y de los prejuicios heredados. Pero una vez más, la capacidad de comprender el pasado, superándolo, depende de la fuerza del espíritu. Nietzsche se pregunta: «¿De dónde procede la energía, la fuerza inflexible, la persistencia con que el individuo, frente a la tradición, trata de adquirir un conocimiento enteramente individual del mundo?» ${ }^{70}$. Con ello Nietzsche nos sugiere que tanto el genio ${ }^{71}$, como el espíritu libre o los «espíritus excepcionales» requieren el poder necesario para enfrentarse a la tradición, es decir, una energía desbordante capaz tanto de crear como de destruir, pero sobre todo capaz de asimilar. Esa fuerza que asimila el «alimento vigorizante» de la tradición, que la convierte, como dice Nietzsche, en «carne y sangre», es la «fuerza plástica», la que hace posible el olvidar y la que hace que el pasado esté vivo en el hombre aunque sea inconscientemente, pues en definitiva la tradición pertenece a la vida.

68. HL $₫ 6$, KSA I 292.

69. HL $\$ 6$, KSA I 293-294.

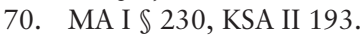

71. Cf. H. W. Siemens, «Nietzsche sobre el genio: Schopenhauer, Wagner y el desplazamiento del Genius por el 'espíritu libre' en los años posteriores a 1870»: Estudios Nietzsche 7 (2007), 99-122. 